\title{
Combination of Boundary Element Method and Genetic Algorithm for Optimization of T-shape Noise Barrier
}

\author{
Sanja GRUBEŠA* Mia SUHANEK, Ivan DJUREK, Antonio PETOŠIĆ
}

\begin{abstract}
This paper presents the acoustic and visual optimization of the T-shape noise barrier cap by using the Boundary Element Method (BEM) fused with the Genetic Algorithm (GA). This paper investigates whether the established methodology in reducing the traffic noise pollution can be applied to the geometry of the T-shape noise barrier cap. By performing the optimization with Genetic Algorithm, it is shown that it is possible to create a noise barrier that provides satisfactory acoustic efficiency at all audio frequencies, from $125 \mathrm{~Hz}$ to $1 \mathrm{kHz}$. The obtained noise barriers are shown to be more efficient compared to conventional wooden T-shape noise barriers. Furthermore, by considering the parameter termed "Visual Pleasantness" it is shown that the opaque barriers are perceived as visually unpleasant when compared to the transparent ones. Based on these findings an optimized design of plain transparent noise barrier which does not diminish the aesthetic performance is proposed.
\end{abstract}

Keywords: Boundary Element Method; Genetic Algorithm; optimization of noise barriers; T-shape noise barrier cap

\section{INTRODUCTION}

Nowadays, each individual is exposed to noise on a daily basis. Noise pollution is often neglected when compared to the other different environmental pollutions (e.g. water pollution, air pollution, soil pollution, thermal pollution etc.). However, same as the all aforementioned pollutions, noise exposure has an accumulating character, meaning that the harmful effect of noise is detected only after a long period of time. Long exposure to noise pollution can be manifested as a bad mood, fatigue, insomnia, headache and loss of concentration, which causes reduced work ability and ultimately permanent hearing impairment.

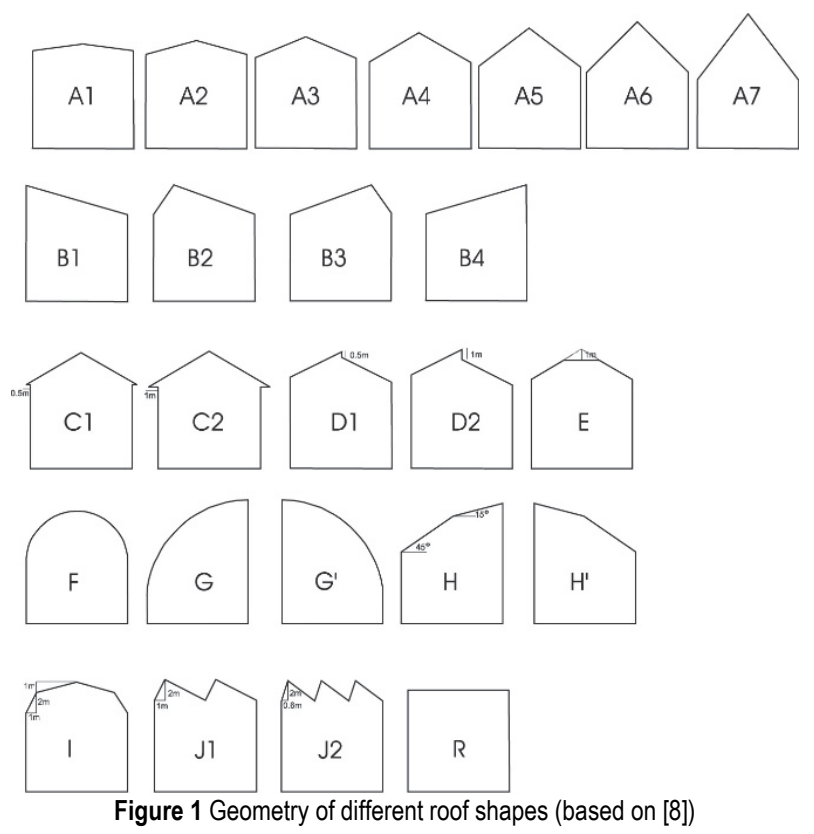

In order to reduce noise pollution, different protection measures can be applied. In terms of traffic noise pollution, reducing the impact of traffic noise on both people and the environments can be achieved by planning and integrating the traffic routes outside the residential areas. In case of existing traffic routes within the residential areas a good solution for reducing the noise levels are noise barriers (see e.g. [1-5]). Here we note that the noise barriers efficiency depends principally on their design.

Several authors have already investigated the geometry of roofs on residential houses and buildings and their influence on sound pressure levels on the receiver side (see e.g. [6-8]). The aforementioned studies have shown that the shape of the roof has a considerable impact on the diffracted sound; thus an adequate choice of roof shape can significantly reduce the sound pressure levels i.e. noise pollution. In [8], the impact of a flat roof has been compared with twenty four uneven roof configurations (Fig. 1).

The obtained results showed that the roof marked respectively $\mathrm{J} 2$ had the best effect in terms of reducing the sound pressure level on the receiving side. The research showed that the roof shape has a significant influence on road traffic noise propagation from a street canyon to a nearby non-directly exposed facade.

In the field of noise barriers, it is already established that the most favourable noise barriers are those which have a diffuse element on the top. In addition, the diffuse element can be circular, Y or T shaped and is usually added on the top of the plain barrier. In particular, the $\mathrm{Y}$ and $\mathrm{T}$ shapes have proven to be a very good choice for the shape of the diffuse elements (see e.g. [12-15]). The optimization of T-shape noise barriers was more thoroughly studied by Baulac et al [9] and Monazam and Lam [10], while Grainer et al [11] explored the Y-shape noise barrier optimization. Ishizuka and Fujiware [12] gave an extensive overview of the acoustic efficiency for several typical diffuse element forms placed at the top of the noise barrier. In [13] a procedure was proposed for improving the acoustic efficiency of noise barriers using top-edge devices. Furthermore, in [14] a procedure was developed for the optimization of well-based designs on the top of road barriers with both thick and very thin bodies by coupling a genetic algorithm with a 2D Dual BEM code. In addition, when placing a noise barrier in residential areas studies have shown that it is also essential to bear in mind the "Visual Pleasantness" of the noise barrier which is the parameter introduced in $[16,17]$.

To extend the aforementioned research in this paper we aim to show that the geometry of the roof can also be 
applied to the geometry of the T-shape noise barrier cap. For this purpose, a 3D computer model of noise barrier with point sound source was developed using Boundary Element Method algorithm [18]. Namely, the idea is to design an optimal noise barrier that satisfies both the acoustic and aesthetical aspect. In particular, the paper proposes a design of a plain transparent noise barrier with optimized cap (obtained with Genetic Algorithm) and sound-absorbent filament (i.e. the noise barrier that conforms unobtrusively to the environment).

\section{THE METHOD}

To determine whether positive influence of the roof geometry can be applicable in noise barrier design, first we have designed and compared four T-shape noise barriers shown in Fig. 2.

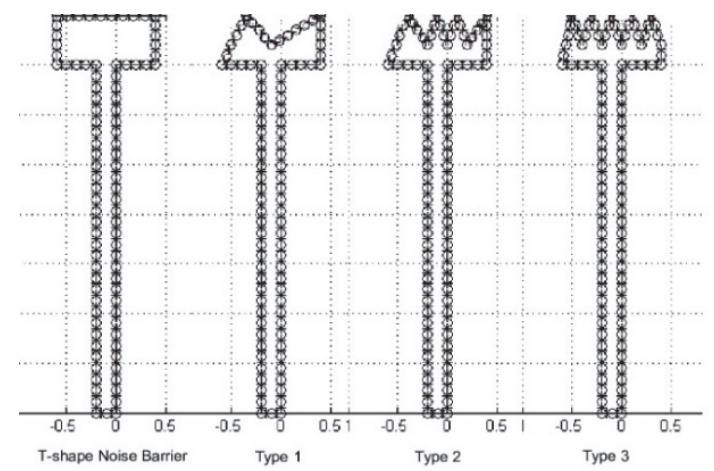

Figure 2 Four types of noise barriers used in this research: T-shape noise barrier used as a reference and types 1 to 3 - T-shape noise barriers with different cap shapes

All the noise barriers were made of wood while the total noise barrier height was 4 meters and the cap height was 0.5 meter. The thickness of the noise barrier was 0.2 meter and the length of the cap was 1 meter.

In this research the T-shape noise barrier is optimized by changing its cap shape, while the type of material has not been altered. Furthermore, all the noise barriers are made of wood and in Tab. 1 the calculated values of the specific acoustic impedance for this type of material are shown. It can be seen that imaginary parts of these impedances are negative. More details can be found in [19].

\begin{tabular}{|c|c|c|c|c|c|c|c|}
\hline \multirow[b]{2}{*}{$\begin{array}{l}n \\
0 \\
0 \\
0 \\
1 \\
\frac{0}{8} \\
0 \\
3\end{array}$} & $\begin{array}{l}\text { Specific } \\
\text { weight } \\
\text { of the } \\
\text { element / } \\
\mathrm{kg} / \mathrm{m}^{2}\end{array}$ & \multicolumn{6}{|c|}{$\begin{array}{l}\text { Imaginary part } \\
\text { of the specific acoustical impedance }(103 \mathrm{~Pa} \cdot \mathrm{s} / \mathrm{m})\end{array}$} \\
\hline & $\stackrel{\infty}{n}$ & $\begin{array}{l}\dddot{\infty} \\
\stackrel{\infty}{\uparrow}\end{array}$ & $\begin{array}{l}\hat{g} \\
\stackrel{\imath}{1}\end{array}$ & $\begin{array}{l}\stackrel{\infty}{\tilde{m}} \\
\stackrel{1}{\ni}\end{array}$ & $\begin{array}{l}\stackrel{0}{N} \\
\infty \\
\stackrel{1}{N}\end{array}$ & 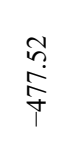 & 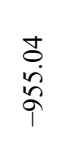 \\
\hline \multicolumn{2}{|c|}{$\begin{array}{c}\text { Frequency } \\
/ \mathrm{Hz}\end{array}$} & 125 & 250 & 500 & 1000 & 2000 & 4000 \\
\hline
\end{tabular}

The acoustic efficiency of these four noise barriers was calculated by determining the noise barrier acoustic efficiency parameter $\left(L_{x i}\right)$ for octave frequencies in the frequency range from 125 to $1000 \mathrm{~Hz}$. The calculation was based on our BEM algorithm [18] design in three- dimensional half-space and all the calculations were made using a computer application that was programmed in $\mathrm{C}++$. Fig. 3 shows a three-dimensional calculated model where the sound source was set 5 meters in front of the noise barrier at 0.5 meter height. This height was chosen according to the results obtained in previous studies [2022] which showed that the sound source location for the combined rolling and engine noise is 0.5 meter above the ground. Furthermore, receiving sound points were at a height of 0.5 meter from the ground, which represents the worst possible case-scenario (e.g. when a direct sound from the sound source is superposed with the reflected sound from the surface of the road, in the frequency range where the sound pressure level of the traffic noise is at its maximum which is about $1 \mathrm{kHz}$ ).

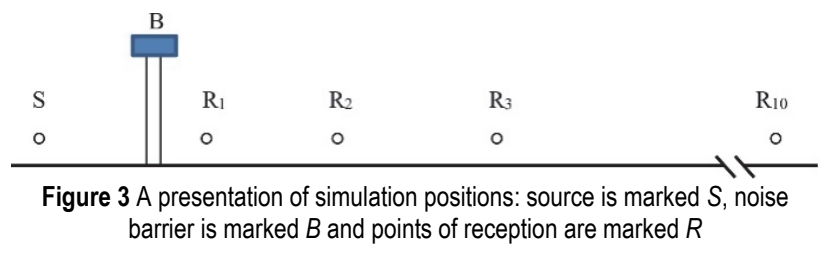

The ground impedance was determined according to Delany-Bazley model [23]. In the calculations presented in this paper it was assumed that the noise barriers were placed on the grass, the surface below the source was asphalt and below the receiving surface was grass again. In order to calculate the noise barrier efficiency parameter $\left(L_{x i}\right)$, the average sound pressure level for receiving sound points located on a vertical line passing through the noise centre was calculated at a distance of 5 to 50 meters from the noise barrier in steps of 5 meters and again at a height of 0.5 meter above the ground. This type of results processing has given a significantly better and more realistic picture of the noise barrier than the usual observation of the samples in several points. Moreover, the optimization itself no longer depends on sound point positions and the optimization results are not influenced with the minimum and maximum positions in the sampling points. In other words, the process of optimization relies on the actual noise barrier optimization envisaged to protect the area behind the noise barrier from noise pollution.

The evaluation of the acoustic noise barrier properties was based on $\Delta L_{\text {rel }}$ values, thus it was calculated as the difference between the average sound pressure level for the reference wooden noise barrier $L_{\text {ref }}$ and the simulated noise barrier $L_{x i}$ as shown in Eq. (1).

$\Delta L_{\text {rel }}=L_{\text {ref }}-L_{-}\left(x_{-} i\right)$

The results obtained for the noise barriers shown in Fig. 2 are presented in Tab. 2.

Table 2 The overall acoustic efficiency of noise barrier types 1 to 3 barriers with respect to the reference wooden T-shape noise barrier

\begin{tabular}{|c|c|c|c|c|c|c|}
\hline $\begin{array}{c}\text { Frequency / } \\
\mathrm{Hz}\end{array}$ & 125 & 250 & 500 & 1000 & $\begin{array}{c}L_{\text {ref }} \\
/ \mathrm{dB}\end{array}$ & \\
\hline $\begin{array}{c}\text { T-shape noise } \\
\text { barrier }\end{array}$ & 62.07 & 51.17 & 59.06 & 51.47 & 57.22 & \\
\hline Barrier type & & & & & $\begin{array}{c}L_{x i} \\
/ \mathrm{dB}\end{array}$ & $\begin{array}{c}\Delta L_{\text {rel }} \\
/ \mathrm{dB}\end{array}$ \\
\hline 1 & 63.90 & 50.21 & 58.34 & 51.71 & 57.79 & -0.58 \\
\hline 2 & 64.15 & 55.23 & 50.38 & 50.28 & 57.05 & 0.17 \\
\hline 3 & 63.71 & 56.11 & 49.10 & 47.73 & 56.59 & 0.63 \\
\hline
\end{tabular}


It can be concluded that the change of the cap shape on the T-shape noise barriers affects the overall noise level, especially at a frequency of $500 \mathrm{~Hz}$. The best result was obtained for type 3 noise barriers at two frequencies (500 $\mathrm{Hz}$ and $1000 \mathrm{~Hz}$ ); however the change of the cap shape proved to be worse than the classical T-shape noise barrier at a lower frequency range. Hence, it can be concluded that it is crucial to start optimizing the T-shape noise barrier cap in order to improve the noise barrier efficiency at lower frequencies.

In order to implement the Genetic Algorithm (GA), the initial population of P1 (40 noise barriers) was created. All noise barriers in P1 are made from the same material (wood) and for each candidate unit the noise barrier acoustic efficiency parameter was calculated. The acoustic efficiency of every candidate unit in each new population of the noise barrier was calculated by determining the acoustic noise barrier efficiency parameter $\left(L_{x i}\right)$ for octave frequencies in the frequency range between 125 and 1000 $\mathrm{Hz}$.

Fig. 4 shows the noise barrier prepared for optimization. It can be noted that from the total height of the barrier cap which is 0.5 meter, the optimization algorithm is "allowed" to change only the upper 0.3 meters.

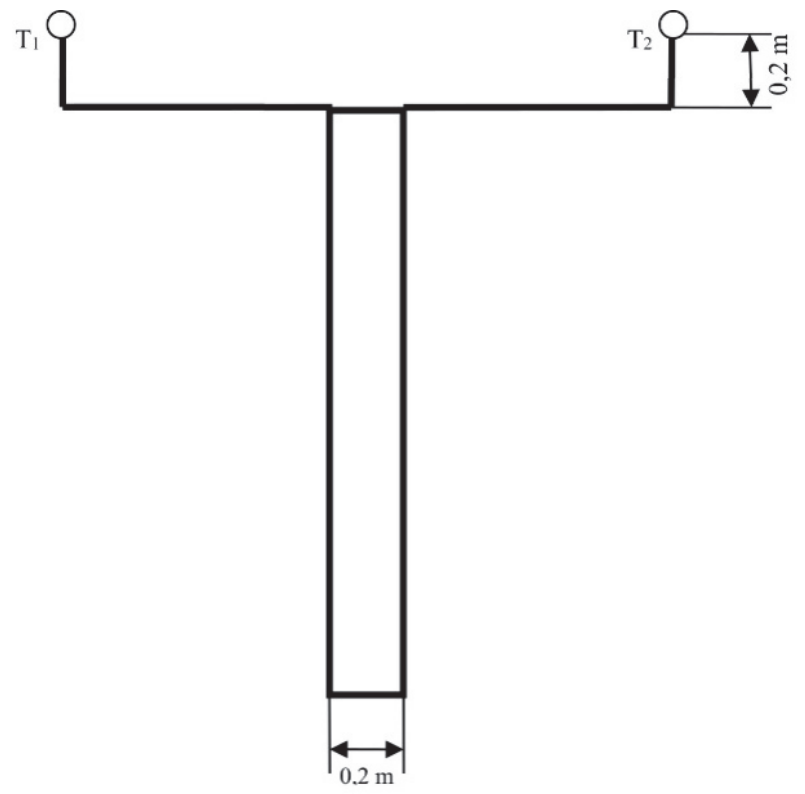

Figure 4 Noise barrier prepared for optimization

In order to provide a higher degree of freedom for the optimization algorithm, the curve describing the appearance of the barrier cap was limited only by two points through which it passes, namely T1 and T2 (Fig. 4). The aforementioned curve is given by the Eq. (2) and this expression is gained from Eq. (3) for ideal rectangular signal [24]. The only difference between the two expressions is that the coefficients in Eq. (2) are arbitrarily and randomly chosen using the optimization algorithm.

$$
\begin{aligned}
& x_{\text {optim }}(t)= \\
& =\frac{4}{\pi\left(\frac{1}{B_{1}} \sin \left(2 B_{1} \pi f t\right)+\frac{1}{B_{2}} \sin \left(2 B_{2} \pi f t\right)+\ldots \frac{1}{B_{20}} \sin \left(2 B_{20} \pi f t\right)\right)}
\end{aligned}
$$

$$
\begin{aligned}
& x_{\text {square }}(t)=\frac{4}{\pi} \sum_{k=1}^{N} \frac{\sin (2 \pi(2 k-1) f t)}{(2 k-1)}= \\
& =\frac{4}{\pi}\left(\sin (2 \pi f t)+\frac{1}{3} \sin (6 \pi f t)+\frac{1}{5} \sin (10 \pi f t)+\cdots\right)
\end{aligned}
$$

Fig. 5 and 6 show the design of two candidate units from the initial population created by the optimization algorithm.
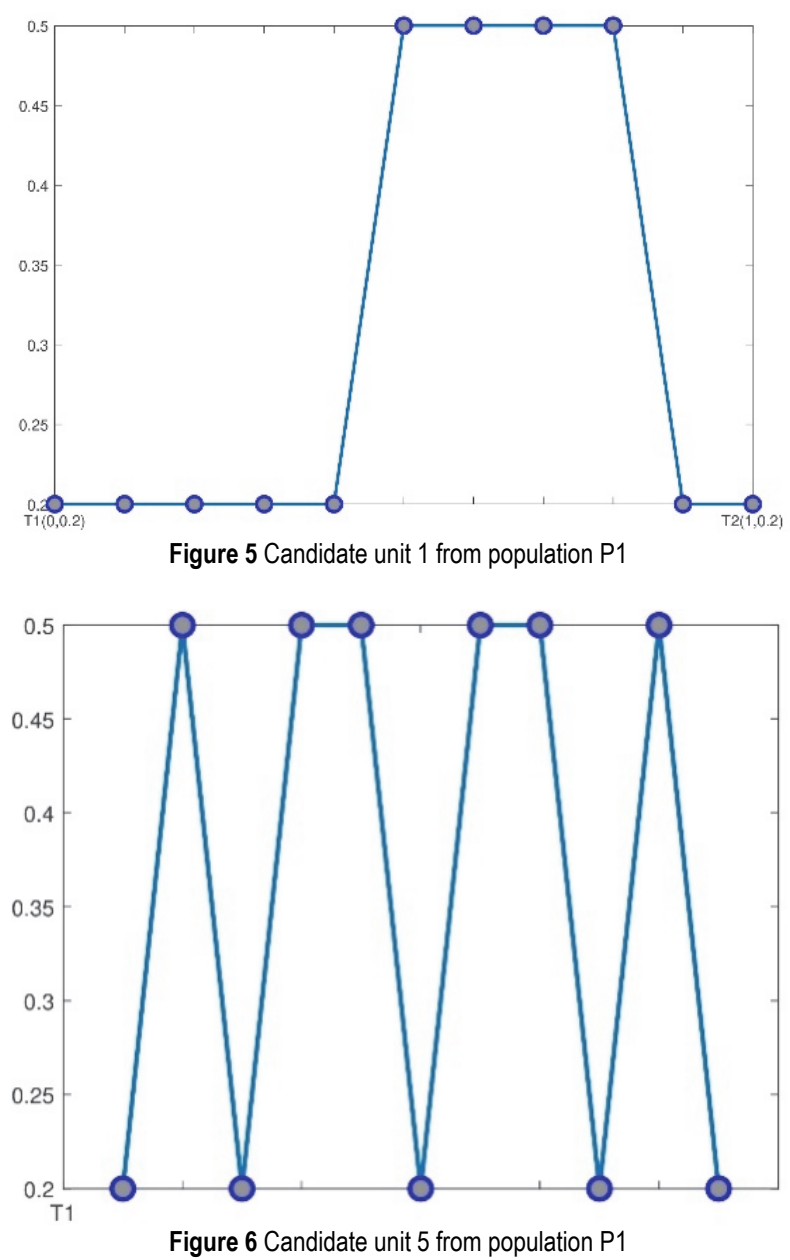

\section{THE RESULTS AND DISCUSSION}

For 40 populations, 40 iterations were made and after 40 iterations the simulation was stopped (i.e. results began to converge). The designed algorithm for the population of 40 candidate units performed 40 iterations and after each iteration the noise barrier efficiency parameter $\left(L_{x i}\right)$ for each noise barrier was calculated. According to the noise barrier efficiency parameter $\left(L_{x i}\right)$, five acoustically best noise barriers were found for each iteration. These five noise barriers always entered a new cycle of iterations, where along these five noise barriers the algorithm created additional 35 barriers according to the Eq. (4) in order to satisfy the requirement for the population size (i.e. 40 candidate units). Finally, after 40 iterations the results began to converge and therefore, the simulation was stopped.

Tab. 3 shows the overall grade of acoustic efficiency of the best noise barrier obtained by the genetic algorithm with respect to the reference wooden T-shape noise barrier. 
Table 3 The overall acoustic efficiency of the best barrier obtained by genetic algorithm with respect to the reference wooden T-shape noise barrier

\begin{tabular}{|c|c|c|c|c|c|c|}
\hline Frequency / Hz & 125 & 250 & 500 & 1000 & $\begin{array}{c}L_{\text {ref }} \\
/ \mathrm{dB}\end{array}$ & \\
\hline $\begin{array}{c}\text { T-shape noise } \\
\text { barrier }\end{array}$ & 62.07 & 51.17 & 59.06 & 51.47 & 57.22 & \\
\hline Barrier type & & & & & $\begin{array}{c}L_{x i} \\
/ \mathrm{dB}\end{array}$ & $\begin{array}{c}\Delta L_{\text {rel }} \\
/ \mathrm{dB}\end{array}$ \\
\hline $\begin{array}{c}\text { Best barrier } \\
\text { obtained by GA }\end{array}$ & 62.07 & 49.50 & 56.84 & 50.49 & 56.25 & 0.97 \\
\hline
\end{tabular}

Fig. 7 shows the acoustic efficiency of the best noise barriers gained in each iteration compared again to the reference wooden $\mathrm{T}$-shape noise barrier. It can be observed that the best barrier was obtained with GA in iteration number 33 , with attenuation greater than $0.97 \mathrm{~dB}$ compared to the reference wooden T-shape barrier.

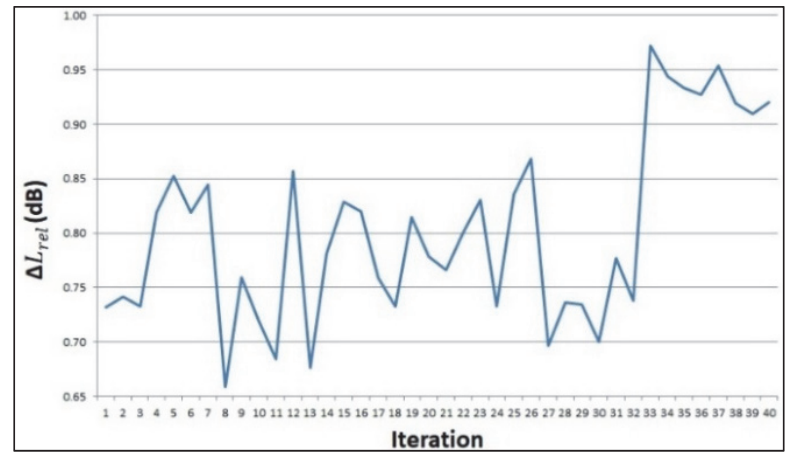

Figure 7 Acoustic efficiency of the best noise barrier in each iteration compared to the reference wooden T-shape noise barrier

Tab. 3 The overall acoustic efficiency of the best barrier obtained by genetic algorithm with respect to the reference wooden T-shape noise barrier.

Fig. 8 shows the average sound pressure level, i.e. the noise barrier acoustic efficiency parameter $\left(L_{x i}\right)$ relative to the distance from the noise barrier position of the reference wooden $\mathrm{T}$-shape noise barrier and the acoustically best barrier obtained from GA. Furthermore, the model of the acoustically best barrier obtained using the GA is shown in Fig. 9.

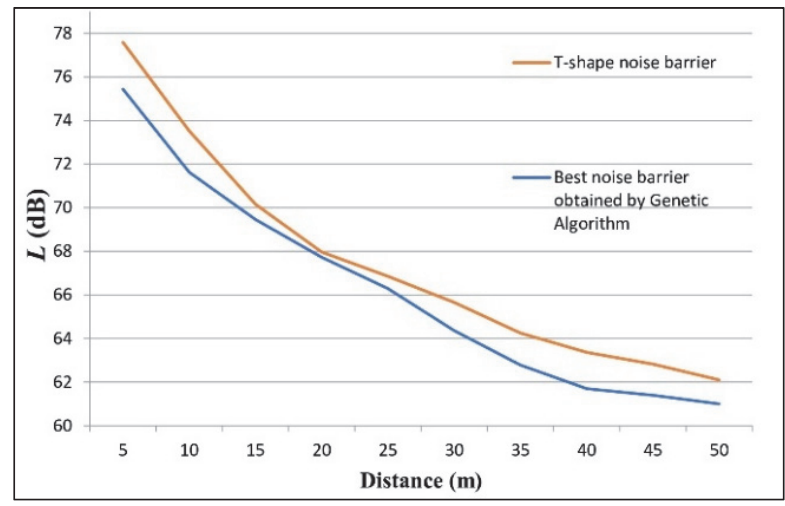

Figure 8 Average sound pressure level for the reference wooden T-shape noise barrier and acoustically best barrier obtained with Genetic Algorithm

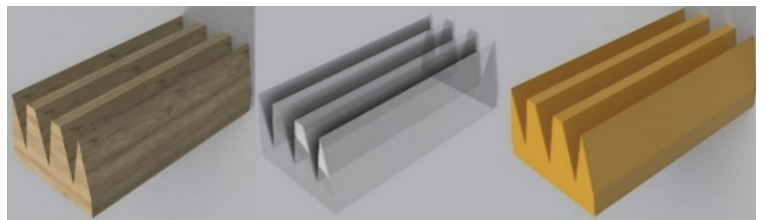

Figure 9 The model of the acoustically best barrier obtained using the Genetic Algorithm

\section{CONCLUSIONS}

Taking into account all of the data collected from this study it can be concluded that Genetic Algorithm optimization of T-shape noise barrier cap has been able to attain a noise barrier model that provides greater acoustic noise barrier efficiency at all observed frequencies, especially for frequencies $250 \mathrm{~Hz}$ and $500 \mathrm{~Hz}$. Furthermore, the best noise barrier obtained from GA when compared to the reference wooden $\mathrm{T}$-shape noise barrier has about $1 \mathrm{~dB}$ increase in the acoustic efficiency noise barrier parameter $\left(L_{x i}\right)$ relative to the distance from the noise barrier position. Therefore, the study has shown that the optimized noise barriers obtained with GA are indeed better than conventional wooden T-shape noise barriers. All of the aforementioned results were achieved only by changing the shape of the noise barrier, in particular the Tshape noise barrier cap. Further improvement of the optimized noise barrier at the lower frequencies $(125 \mathrm{~Hz}$ and $250 \mathrm{~Hz}$ ) has been accomplished by adding the soundabsorbent material to the noise barrier. In addition, the "Visual Pleasantness" component has been incorporated in the optimization process. Bearing in mind an interdisciplinary approach to noise barriers (acoustical and aesthetical) the paper proposes a new noise barrier design in a form of plain transparent noise barrier that has a cap on its top. The cap on its top has a sound-absorbent filling which increases the acoustical features while at the same time does not appear obtrusive. We eventually note the proposed type of noise barriers can in addition be coloured with vivid colours and in that way represent sort of city ornaments or even landmarks, thereby becoming even more visually pleasant to the city habitants.

\section{Acknowledgements}

This work has been supported by the European Union from European regional development fund (ERDF) under the project number KK.01.2.1.01.0103 Acoustical Camera (in Croatian: Akustička kamera).

\section{REFERENCES}

[1] Radosz, J. (2019). Acoustic performance of noise barrier based on sonic crystals with resonant elements. Applied Acoustics, 155, 492-499. https://doi.org/10.1016/j.apacoust.2019.06.003

[2] Ishizuka, T. \& Fujiwara, F. (2004). Performance of noise barriers with various edge shapes and acoustical conditions. Applied Acoustics, 65, 125-141. https://doi.org/10.1016/j.apacoust.2003.08.006

[3] Koussa, F., Defrance, J., Jean, P., \& Blanc-Benon, P. (2017). Acoustical Efficiency of a Sonic Crystal Assisted Noise Barrier. Acta Acustica united with Acustica, 99(3), 399-409. https://doi.org/10.3813/AAA.918621

[4] Grubeša, S., Domitrović, H., \& Jambrošić, K. (2011). Performance of traffic noise barriers with varying crosssection. Promet - Traffic \& Transportation, 23, 161-168. https://doi.org/10.7307/ptt.v23i3.119

[5] Fard Samaneh, M. B., Peters, H., Marburg, S., \& Kessissoglou, N. (2017). Acoustic Performance of a Barrier Embedded With Helmholtz Resonators Using a QuasiPeriodic Boundary Element Technique. Acta Acustica united with Acustica, 103(3), 444-450.

https://doi.org/10.3813/AAA.919074 
[6] Renterghem, T. \& Botteldooren, D. (2003). Numerical simulation of sound propagation over rows of houses in the presence of wind. Proceedings of 10th International Congress on Sound and Vibration (ICSV 2003), 1381-1388.

[7] Heimann, D. (2007). Three-dimensional linearised Euler model simulations of sound propagation in idealised urban situations with wind effects. Applied Acoustics, 68, 217-237. https://doi.org/10.1016/j.apacoust.2005.10.002

[8] Renterghem, T. \& Botteldooren, D. (2009). The importance of roof shape for the urban acoustic environment EURONOISE 2009.

[9] Baulac, M., Defrance, J., \& Philippe, J. (2008). Optimisation with genetic algorithm of the acoustic performance of $\mathrm{T}$ shaped noise barriers with a reactive top surface. Applied Acoustics, 69(4), 332-342. https://doi.org/10.1016/j.apacoust.2006.11.002

[10] Monazzam, M. R. \& Lam, Y. W. (2008). Performance of Tshape barriers with top surface covered with absorptive quadratic residue diffusers. Applied Acoustics, 69(2), 93109. https://doi.org/10.1016/j.apacoust.2006.10.006

[11] Greiner, D., Aznárez, J. J., Maeso, O., \& Winter, G. (2010). Single- and multi-objective shape design of Y-noise barriers using evolutionary computation and boundary elements. Advances in Engineering Software, 41(2), 368-378. https://doi.org/10.1016/j.advengsoft.2009.06.007

[12] Ishizuka, T. \& Fujiwara, F. (2004). Performance of noise barriers with various edge shapes and acoustical conditions. Applied Acoustics, 65(2), 125-141. https://doi.org/10.1016/j.apacoust.2003.08.006

[13] Toledo, R., Aznárez, J. J., Maeso, O., \& Greiner, D. (2015). A Procedure for Improving the Acoustic Efficiency of TopEdge Devices on Noise Barriers: An Application of Genetic Algorithms and Boundary Elements", Chapter in a book: Evolutionary Algorithms and Metaheuristics in Civil Engineering and Construction Management 2015.

[14] Toledo, R., Aznárez, J. J., Greiner, D., \& Maeso, O. (2016). Shape design optimization of road acoustic barriers featuring top-edge devices by using genetic algorithms and boundary elements. Engineering Analysis with Boundary Elements, 63, 49-60. https://doi.org/10.1016/j.enganabound.2015.10.011

[15] Costaa, G. de A., Godinhob, L. M. C., Santiagoa, J. A. F., Mansura, W. J., \& Petersa, F. C. (2019). Application of the method of fundamental solutions to predict the acoustic performance of T-shaped thin barriers. Engineering Analysis with Boundary Elements, 99, 142-156. https://doi.org/10.1016/j.enganabound.2018.11.009

[16] Maffei, L., Masullo, M., \& Aletta, F. (2012). Influence of the design of railway noise barriers on soundscape perception. Internoise 2012. https://doi.org/10.13140/2.1.4899.9369

[17] Maffei, L., Masullo, M., Aletta, F., \& Gabriele, M. (2013). The influence of visual characteristics of barriers on railway noise perception. Science of the Total Environment, 445-446, 41-47. https://doi.org/10.1016/j.scitotenv.2012.12.025

[18] Grubeša, S., Jambrošić, K., \& Domitrović, H. (2012). Noise barriers with varying cross-section optimized by genetic algorithms. Applied Acoustics, 73(11), 1129-1137. https://doi.org/10.1016/j.apacoust.2012.05.005

[19] Morse, M. P. Vibration and Sound. Acoustical Society of America.

[20] Baulaca, M., Guilloub, A., Defrancea, J., \& Jeana, P. A. H. (2008). Calculations of low height noise barriers efficiency by using Boundary Element Method and optimisation algorithms. The Journal of the Acoustical Society of America, 223-227.

[21] Nilsson, M., Bengtsson, J., \& Klaeboe, R. (2014). Environmental Methods for Transport Noise Reduction. Taylor \& Francis Group.

[22] Jonasson, H. G. (2007). Acoustical Source Modelling of Road Vehicles. Acta Acustica united with Acustica, 93, 173184.
[23] Delany, M. \& Bazley, E. N. (1970). Acoustical properties of fibrous absorbent materials. Applied Acoustics, 3, 105-116. https://doi.org/10.1016/0003-682X(70)90031-9

[24] Tang, K. T. Mathematical Methods for Engineers and Scientists: Fourier analysis, partial differential equations and variational models. Springer.

\section{Contact information:}

Sanja GRUBEŠA, Postdoc. Researche

(Corresponding author)

University of Zagreb, Faculty of EE and Computing,

Unska 3, 10000 Zagreb, Croatia

E-mail: sanja.grubesa@fer.hr

Mia SUHANEK, Postdoc. Researcher

University of Zagreb, Faculty of EE and Computing,

Unska 3, 10000 Zagreb, Croatia

E-mail:mia.suhanek@fer.hr

Ivan DJUREK, Full Professor

University of Zagreb, Faculty of EE and Computing,

Unska 3, 10000 Zagreb, Croatia

E-mail: ivan.djurek@fer.hr

Antonio PETOŠIĆ, Associate Professor

University of Zagreb, Faculty of EE and Computing,

Unska 3, 10000 Zagreb, Croatia

E-mail: antonio.petosic@fer.hr 